Objectives: To assess in a real-world, observational study whether treatment with $A B A$ had a similar malignancy risk as other biologics, with or without MTX, when used as the initial bDMARD for RA.

Methods: The Truven MarketScan ${ }^{\circledR}$ Commercial and Supplemental Medicare databases were used to identify adult pts diagnosed with RA who initiated bDMARD treatment with ABA or another bDMARD between Jan 2007 and Dec 2014. Other bDMARDs included adalimumab, anakinra, certolizumab, etanercept, golimumab, infliximab, rituximab and tocilizumab. Pts were required to have $\geq 6$ months $(\mathrm{M})$ of continuous health plan enrolment before bDMARD initiation (index date) and deemed to have initiated a treatment if there was no claim for any bDMARD in the limited $6 \mathrm{M}$ period before bDMARD initiation. Pts who had a malignancy in the baseline $6 \mathrm{M}$ period were excluded. Pts were followed up from the date of the first bDMARD prescription initiation, either ABA or another bDMARD, until occurrence of a malignancy (identified by ICD-9 diagnosis code), end of enrolment in the database or end of data collection, whichever occurred first. A 6M latency period was included. Propensity scores of ABA initiation were estimated from the baseline covariates using a logistic regression model, and trimmed to include only pts with ranges common to both ABA-exposed and comparator bDMARD cohorts. The Cox proportional hazard regression model was used to provide an estimate of the hazard ratio $(\mathrm{HR})$ of malignancy associated with $\mathrm{ABA}$ initiation compared with initiation of another bDMARD, adjusted for age and deciles of the propensity score after trimming.

Results: A total of 5391 pts were identified as above as having initiated bDMARD therapy with $\mathrm{ABA}$ and 74,315 initiated with another bDMARD, with follow-up of $<8$ yrs (mean $2.1 \mathrm{yrs}$ ). Pts who initiated ABA vs other bDMARDs were older (mean 55 vs 52 yrs), had more co-morbidity, used less MTX (49 vs 57\%) and more other non-bDMARD (41 vs $36 \%$ ) at baseline. After trimming on propensity scores, 565 pts developed a malignancy after ABA (incidence rate 5.0 per 100/yr) compared with 5750 after another bDMARD (incidence rate 3.6 per 100/yr). The adjusted $\mathrm{HR}(95 \% \mathrm{Cl})$ of any malignancy with ABA initiation relative to other bDMARDs was $1.18(1.06,1.30)$, while for any malignancy excluding non-melanoma skin cancer it was $1.17(1.02,1.34)$. The risk $(\mathrm{HR} ; 95 \% \mathrm{Cl})$ was not significantly elevated for lung cancer $(1.11 ; 0.70,1.76)$, female breast cancer $(1.21 ; 0.91$, 1.62) and lymphoma $(1.21 ; 0.77,1.90)$

Conclusions: In this large, real-world study of pts treated for RA, the incidence of the most common malignancies of breast, lung and lymphoma were not significantly increased in pts using abatacept as first-line bDMARD treatment compared with other bDMARDs, though the confidence intervals were wide. The slight increase in the risk of overall malignancy with abatacept needs further investigation, particularly to assess the potential for residual confounding and the impact of the short baseline period.

References:

[1] Mercer LK, et al. Ann Rheum Dis 2015;74:1087-93.

Disclosure of Interest: S. Suissa Consultant for: Bristol-Myers Squibb, S. Dell'Aniello: None declared, T. Simon Shareholder of: Bristol-Myers Squibb, Employee of: Bristol-Myers Squibb

DOI: 10.1136/annrheumdis-2017-eular.2887

\section{FRI0130 RATES AND RISK FACTORS OF NEW-ONSET PSORIASIS UNDER DIFFERENT BIOLOGIC AGENTS AND CONVENTIONAL} SYNTHETIC DMARD TREATMENT

A. Strangfeld ${ }^{1}$, L. Baganz ${ }^{1}$, A. Richter ${ }^{1}$, B. Manger ${ }^{2}$, G.-R. Burmester ${ }^{3}$ C. Eisterhues ${ }^{4}$, S. Wassenberg ${ }^{5}$, A. Zink ${ }^{1,3}$, J. Listing ${ }^{1}$. ${ }^{1}$ German Rheumatism Research Center, Berlin; ${ }^{2}$ Scientific Advisory Board, Erlangen; ${ }^{3}$ Charité University Medicine, Berlin; ${ }^{4}$ Rheumatologist, Braunschweig; ${ }^{5}$ Rheumatologist, Ratingen, Germany

Background: Psoriatic skin disease is a burdensome, sometimes painful, dermatologic condition which was reported to occur as an adverse event $(A E)$ during TNF-inhibitor (TNFi) treatment of rheumatoid arthritis (RA). Single case reports revealed the occurrence of psoriasis also during treatment with non-TNFi, but the magnitude under those agents remains unclear.

Objectives: To compare incidence rates of psoriasis in RA under treatment with different biologic and conventional synthetic (b/cs)DMARDs and to investigate risk factors.

Methods: We used data of 12,722 patients (53,585 patient years (py)) enrolled with the start of a b/csDMARD in the German biologics register RABBIT. Patients were required to have no psoriasis at baseline and at least one follow-up. All psoriatic events (PsE) reported until 30 April 2016 were selected and assigned to treatments administered within 3 months prior to the event. Crude incidence rates (IR) of PsE were calculated per 1,000py. Cox regression was applied to investigate risk factors for the occurrence of PsE with and without inverse probability weights (IPW) to adjust for confounding by indication.

Results: 96 PsE were reported, with only 6 of them categorized as being serious. The median time between enrollment in the cohort and onset of psoriasis was 19 months (IQR:11-45 months). 21 of all PsE (22\%) were palmoplantar manifestations of which 9 were reported as pustular type.

Compared to csDMARD treatment with a crude IR of $0.44 / 1,000$ py $(95 \% \mathrm{Cl}$ $0.2 ; 0.9)$, the IRs found under TNFi (IR $2.99(95 \% \mathrm{Cl} 2.3 ; 3.8)$ ) and abatacept (IR $3.99(95 \% \mathrm{Cl} 1.7 ; 7.9))$ were significantly higher. In patients treated with rituximab (IR $1.8(95 \% \mathrm{Cl} 0.8 ; 3.4))$ or tocilizumab (IR $0.7(95 \% \mathrm{Cl} 0.1 ; 2.0))$ IRs for PsE were not significantly different from csDMARD patients. Across TNFi, the IR varied insignificantly.

Adjusted regression analysis showed higher risk for PsE with TNFi, abatacept and rituximab (graph). Female sex (adjusted hazard ratio (HR) $1.8(1.0 ; 3.3)$ ) and being rheumatoid factor negative (HR $1.6(1.0 ; 2.6))$ were additional significant risk factors. Smoking (HR $1.6(1.0 ; 2.5)$ ), age (HR $1.0(0.98 ; 1.01)$ ), glucocorticoids per $5 \mathrm{mg} / \mathrm{d}$ increase (HR $1.1(1.0 ; 1.2)$ ), and prior (<6months) skin infections (HR $2.2(0.5 ; 9.7)$ ) were not significantly associated. Replacing glucocorticoids with DAS28 did not show differing results. Adjustment with IPW attenuated the effect of rheumatoid factor $(p=0.4)$ but smoking was significantly associated with a higher risk $(p<0.01)$.

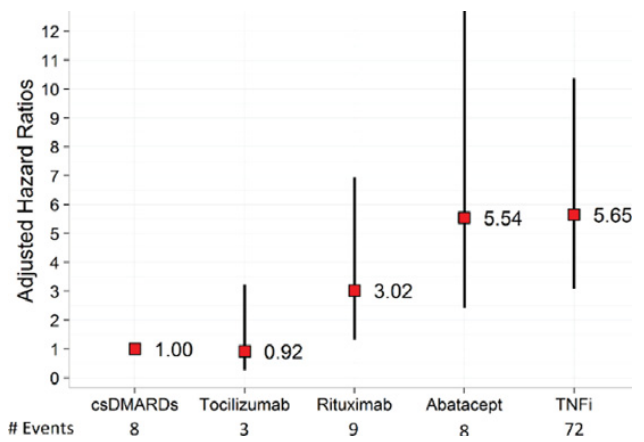

Conclusions: This is the first analysis comparing the incidence of psoriasis under biologics with different modes of action within one cohort. Our results confirmed a higher risk for $\mathrm{TNFi}^{1}$ and showed a similar result for abatacept. A lower but still significant increased risk was found for rituximab, whereas there was no difference for tocilizumab compared to csDMARDs. New onset psoriasis is a rare and most often non-serious event. The number needed to harm is 334 patients treated with TNFi for one year to observe one PsE.

Acknowledgements RABBIT is supported by a joint, unconditional grant from AbbVie, BMS, Celltrion, MSD, Pfizer, Roche, Samsung and UCB.

References:

[1] Hernandez et al., Arthritis Care Res 2013; 65:2024-31.

Disclosure of Interest: A. Strangfeld Speakers bureau: BMS, MSD, Pfizer, Roche, Sanofi-Aventis, L. Baganz: None declared, A. Richter Consultant for: Pfizer, B. Manger Consultant for: Abbvie, BMS, MSD, Pfizer, Roche, UCB, G.-R. Burmester Consultant for: AbbVie, BMS, MSD, Pfizer, Roche, UCB, C. Eisterhues: None declared, S. Wassenberg Consultant for: AbbVie, Pfizer, Novartis, Janssen, Roche-Chugai, Celltrion, BMS, Fuji, Speakers bureau: AbbVie, Celgene, Novartis, Pfizer, MSD, Lilly, Janssen, UCB, A. Zink Speakers bureau: AbbVie, BMS, MSD, Pfizer, Roche, UCB, J. Listing Consultant for: Sandoz, Pfizer

DOI: 10.1136/annrheumdis-2017-eular.5092

\section{FRI0131 THE 2010 ACR/EULAR CRITERIA ARE INSUFFICIENTLY ACCURATE IN THE EARLY IDENTIFICATION OF AUTOANTIBODY-NEGATIVE RHEUMATOID ARTHRITIS: RESULTS FROM THE LEIDEN-EAC AND ESPOIR COHORTS}

D. Boeters ${ }^{1}$, C. Gaujoux-Viala ${ }^{2}$, A. Constantin ${ }^{3}$, A. van der Helm-van Mil ${ }^{1}$ ${ }^{1}$ Department of Rheumatology, Leiden University Medical Center, Leiden, Netherlands; ${ }^{2}$ Department of Rheumatology, Nîmes University Hospital; EA2415, Montpellier University, Nîmes; ${ }^{3}$ Department of Rheumatology, Centre Hospitalier Universitaire de Toulouse, Hôpital Purpan, Toulouse, France

Background: The 2010-ACR/EULAR criteria were derived to classify RA earlier in time. Previous studies indeed observed that the 2010-criteria were fulfilled earlier than the 1987-criteria. This study determined whether the 2010-criteria perform equally in the early detection of autoantibody-positive and autoantibody-negative RA.

Objectives: To compare the performance of the 2010-criteria between autoantibody-positive and autoantibody-negative RA within two different early arthritis cohorts.

Methods: From the total Leiden-EAC ( $n=3448)$ and ESPOIR ( $n=813)$ RA-patients who fulfilled the 1987-RA criteria at 1-year but not at presentation were selected ( $n=515$ and $n=53$, respectively). These RA-patients were studied on the presence of ACPA and RF, and on fulfilling the 2010-criteria at baseline, as 2010-positivity indicated that these RA-patients were earlier identified.

Results: In the EAC, $67 \%$ of the selected RA-patients did already fulfil the 2010-criteria at baseline. In ESPOIR this was 57\%, indeed demonstrating early classification with the 2010-criteria. Among the selected autoantibody-positive RA-patients of the EAC, $85 \%$ was identified at baseline already with the 2010criteria. Within autoantibody-negative RA this was $45 \%(p<0.001)$. Similarly within autoantibody-positive RA-patients in ESPOIR 92\% was 2010-positive at baseline, whereas this was only $25 \%$ within autoantibody-negative RA $(p<0.001)$.

Conclusions: The 2010-criteria perform well in the early identification of autoantibody-positive RA, but autoantibody-negative RA-patients are still frequently missed with these criteria. As it has been demonstrated that early 
treatment initiation is beneficial for the outcome of ACPA-negative RA as well, other diagnostics are required for the early identification of ACPA-negative RA. Disclosure of Interest: None declared

DOI: 10.1136/annrheumdis-2017-eular.3994

\section{FRI0132 HIGH DISEASE ACTIVITY IS A PREDICTOR OF DEPRESSION AND PERSISTENT DEPRESSION IN EARLY RHEUMATOID ARTHRITIS: RESULTS FROM THE ONTARIO BEST PRACTICES RESEARCH INITIATIVE (OBRI)}

R. Joshi ${ }^{1}$, M. Movahedi ${ }^{2,3}$, E. Rampakakis ${ }^{2}$, A. Cesta ${ }^{3}$, X. Li $^{3}$, S. Couto ${ }^{3}$, J. Sampalis ${ }^{2}$, C. Bombardier ${ }^{3,4,5}$, B. Kuriya ${ }^{6}$ on behalf of OBRI investigators. ${ }^{1}$ Department of Rheumatology, Brampton Civic Hospital, William Osler Health System, Brampton; ${ }^{2}$ JSS Medical Research, Montreal; ${ }^{3}$ Ontario Best Practices Research Initiative, Toronto General Hospital, University Health Network; ${ }^{4}$ Division of Rheumatology, Mount Sinai Hospital; ${ }^{5}$ Department of Medicine (DOM) and Institute of Health Policy, Management, and Evaluation (IHPME);

${ }^{6}$ Sinai Health System, University of Toronto, Toronto, Canada

Background: The prevalence of depression among individuals with rheumatoid arthritis (RA) may be as high as $40 \%$ but persistence of depression over time is relatively unknown. Uncontrolled inflammation may drive severe disease and, in turn, inflammation and high disease activity are hypothesized to mediate depressive symptoms.

Objectives: The aims of this analysis were to: (1) describe the prevalence of depression at baseline and determine how often depression persists over time; (2) determine whether there is an association between changes in disease activity and depression over time among individuals with early RA (ERA).

Methods: ERA patients enrolled in the Ontario Best Practices Research Initiative (OBRI) with ERA ( $\leq 1$ year disease duration) and $\geq 2$ years of follow-up were included. Persistent depression was defined as self-reported depression at baseline and at $>50 \%$ of visits over the first 2 years. The association between baseline disease activity, measured by the Clinical Disease Activity Index (CDAl), and depression at baseline or persistent depression was evaluated with multivariate logistic regression. The General Estimation Equation was also used to explore the association between changes in CDAI disease activity over time and risk of depression.

Results: 469 patients with ERA $(72.9 \%$ female) were included with a mean (SD) age of 56.8 (13.6) years. Mean (SD) disease parameters were: CDAl: 22.9 (14.1); DAS28: 4.6 (1.5); and HAQ disability Index: 1.1 (0.75). At baseline, the prevalence of depression was $26 \%$, and $23 \%$ reported persistent depression. Persistent depression was significantly higher in patients with moderate CDAI $(19 \%)$ and high CDAl $(29 \%)$ compared to those in CDAl low disease activity (LDA) or remission $(16 \%, \mathrm{p}=0.02)$. After adjusting for potential confounders (sex, rheumatoid factor status, prior use of csDMARDs, current use of bDMARDs, HAQ disability index, number of comorbidities), increased CDAI at baseline was significantly associated with both baseline depression and persistent depression (OR: $1.04 ; 95 \% \mathrm{Cl}: 1.01-1.06, \mathrm{p}=0.002$ ). Female gender (OR: $3.17 ; 95 \% \mathrm{Cl}$ : $1.50-6.68 p=0.002$ ) and greater number of comorbidities at baseline (OR: 1.68; $95 \%$ Cl: $1.47-1.93, p<0.001)$ were also associated with persistent depression. Over the course of follow-up, the risk of depression was significantly higher among patients with moderate disease activity compared to those in CDAI LDA or remission (OR: 1.16; $95 \% \mathrm{Cl}: 1.04-1.29, \mathrm{p}=0.006$ ). The risk of depression was substantially greater for those with high disease activity (OR: 1.32; $95 \% \mathrm{Cl}$ : 1.15-1.52) over time compared to those achieving LDA or remission states.

Conclusions: Depression in ERA is common and initial high disease activity increases the risk of depression as well as its persistence. High CDAl during the early years of follow-up was also an independent predictor of depression. This highlights the importance of intervening during the "window of opportunity" to control disease activity and the potential to mitigate adverse health outcomes, including depression.

Disclosure of Interest: R. Joshi Grant/research support from: OBRI was funded by peer reviewed grants from CIHR (Canadian Institute for Health Research), Ontario Ministry of Health and Long-Term Care (MOHLTC), Canadian Arthritis Network (CAN) and unrestricted grants from: Abbvie, Amgen, Celgene, Hospira, Janssen, Lilly, Novartis, Merck, Pfizer, Roche, Sanofi, \& UCB, M. Movahedi Employee of: OBRI/JSS Medical Research, E. Rampakakis Employee of: JSS Medical Research, A. Cesta Employee of: OBRI, X. Li Employee of: OBRI, S. Couto Employee of: OBRI, J. Sampalis Employee of: Head of JSS Medical Research, C. Bombardier Grant/research support from: OBRI was funded by peer reviewed grants from CIHR (Canadian Institute for Health Research), Ontario Ministry of Health and Long-Term Care (MOHLTC), Canadian Arthritis Network (CAN) and unrestricted grants from: Abbvie, Amgen, Celgene, Hospira, Janssen, Lilly, Novartis, Merck, Pfizer, Roche, Sanofi, \& UCB, B. Kuriya Grant/research support from: OBRI was funded by peer reviewed grants from CIHR (Canadian Institute for Health Research), Ontario Ministry of Health and Long-Term Care (MOHLTC), Canadian Arthritis Network (CAN) and unrestricted grants from: Abbvie, Amgen, Celgene, Hospira, Janssen, Lilly, Novartis, Merck, Pfizer, Roche, Sanofi, \& UCB

DOI: 10.1136/annrheumdis-2017-eular.2311

\section{FRI0133 IS THERE INCREMENTAL MENTAL HEALTH BURDEN ASSOCIATED WITH RHEUMATOID ARTHRITIS?}

V. Strand ${ }^{1}$, M. Kosinski ${ }^{2}$, R. Rendas-Baum ${ }^{2}$, D. Brooks ${ }^{3}$, R. Ganguly ${ }^{3}$.

${ }^{1}$ Stanford University, Palo Alto, CA; ${ }^{2}$ Optum, Inc., Eden Prairie, MN:

${ }^{3}$ GlaxoSmithKline, Collegeville, $P$, United States

Background: Rheumatoid arthritis (RA) patients are more likely to experience depression. ${ }^{1}$ This comorbidity is associated with increased disability, use of healthcare services, and mortality risk. ${ }^{2,3}$ The association between RA and other mental health disorders has received limited attention and there remains a need to further demonstrate and understand the impact of RA on mental health.

Objectives: Evaluate the mental health burden of RA patients based on the analysis of Short Form-36v2 Health Survey (SF-36v2) mental health (MH) and role emotional (RE) domain scores from two independent general population databases in the US and Europe.

Methods: The mental health burden associated with RA was analyzed by comparing mean SF-36v2 MH and RE scores of individuals self-reporting RA (with or without depression) and the scores from 2 benchmark samples (individuals without RA, individuals with depression and no RA) in two large cross-sectional survey studies (QualityMetric's 2009 General US Population Norming Study of the SF-36v2 and the 2014 European National Health and Wellness Survey). Multivariate regression methods were used to adjust each benchmark sample to the distribution of the RA sample in terms of age and gender. Differences between samples were interpreted with respect to minimally important differences: 3 points for $\mathrm{MH} ; 4$ points for RE.

Results: The US (2009) and European (2014) samples included 4,042 and 81,366 individuals, respectively. Compared with individuals without RA or depression, mean $\mathrm{RE}$ scores were significantly $(P<0.001)$ lower for RA patients without depression in the US (-7.75 points) and Europe (-5.31 points). Likewise, mean MH scores were significantly $(P<0.001)$ lower among RA patients without depression in the US (-4.85 points) and Europe ( -5.03 points) compared with individuals without RA or depression. Compared to individuals with depression and no RA, mean RE and $\mathrm{MH}$ scores were 5 to 10 points higher $(P<0.001)$ for RA patients without depression in both the US and Europe. Comparisons of RE and MH scores between RA patients with and without comorbid depression showed that comorbid depression was associated with 2 to 6 points lower scores $(P<0.01)$ in $\mathrm{RE}$ and $\mathrm{MH}$ domains, in both the US and Europe.

Conclusions: RA is associated with significant and clinically meaningful mental health burden as measured by SF-36v2 MH and RE domains. Results comparing scores between RA patients with and without comorbid depression suggest that there is an incremental mental health burden associated with RA, often exceeding minimally important differences among US patients.

References:

[1] Dickens C, et al. Psychosomatics. 2003:44(3):209-215.

[2] Ang DC, et al. J Rheumatol. 2005;32(6):1013-1019.

[3] Kessler RC, et al. J Occupat Environ Med. 2003;45(12):1257-1266.

Disclosure of Interest: V. Strand Consultant for: Abbvie, Amgen, AstraZeneca, Biogenldec, Boehringer Ingelheim, Celltrion, Crescendo, Genentech/Roche, GSK, Janssen, Lilly, Merck, Novartis, Pfizer, Regeneron, Samsung, Sanofi and UCB, M. Kosinski Employee of: Optum, R. Rendas-Baum Employee of: Optum, D. Brooks Shareholder of: GlaxoSmithKline, Employee of: GlaxoSmithKline, R. Ganguly Shareholder of: GlaxoSmithKline, Employee of: GlaxoSmithKline

DOI: 10.1136/annrheumdis-2017-eular.3575

\section{FRI0134 CLUSTER ANALYSIS OF PULMONARY LESIONS IN RHEUMATOID ARTHRITIS (RA); AIRWAY DISEASE IS SHARED AND CRITICAL PULMONARY ABNORMALITY IN RA}

A. Tanaka, Y. Namiki, R. Yamazaki, H. Okada, S. Arai, T. Owada, R. Maezawa, M. Arima, K. Kurasawa. Departoment of Rheumatology, Dokkyo Medical University, Shimotuga-Gun, Japan

Background: Rheumatoid arthritis (RA) is a systemic inflammatory disease that affects joints and various organs including the lung. The pulmonary involvement is critical for prognosis of the patients and decision of the treatment. Moreover, the pulmonary involvement showed various abnormalities such as interstitial pneumonia (ILD) and airway disease (AD). Importantly, a pulmonary abnormality coexists with other ones in RA patients. There have been large numbers of studies on the prevalence of pulmonary abnormalities and clinical features of patients with these lesions. However, it remains to be elucidated what existence pattern of pulmonary abnormalities RA patients have.

Objectives: To reveal the existence pattern of the pulmonary abnormalities in RA patients using cluster analysis, and to clarify the clinical features of patients with multiple pulmonary abnormalities.

Methods: Subjects were consecutive 208 RA patients who were treated with bDMARDs as the first one from Feb. 2004 to Sep. 2015 in our department and received HRCT scan before and after the therapy. Pulmonary abnormalities were classified into 4 categories (ILD, nodular lesions, AD and other) and 20 lesions such as ground-glass opacity, reticular pattern, bronchiolitis and bronchiectasis and were examined their existence and distribution. Cluster analysis was conducted according to the existence of the lesions by Ward method. Clinical features were analyzed through reviewing medical records.

Results: Subjects were 208 RA cases (M/F; 64/144, mean age 59.2 year-old, 